\title{
Lung clearance of soluble radioaerosols of different molecular weights in systemic sclerosis
}

\author{
SAWTANTRA K CHOPRA, GEORGE V TAPLIN, DONALD P TASHKIN, AND \\ DENNIS ELAM
}

From the Division of Pulmonary Disease, Department of Medicine and Laboratory of Nuclear Medicine and Radiation Biology, and Department of Radiological Sciences, UCLA School of Medicine, Los Angeles, California 90024, USA

\begin{abstract}
Clearance rates of soluble radioaerosols of sodium pertechnetate $\left({ }^{99} \mathrm{mcO}_{4} ; \mathrm{mol}\right.$ wt 163$)$ and diethylenetriaminepenta-acetate ( ${ }^{99 \mathrm{~m}}$ Tc-DTPA; mol wt 492) were determined in seven normal subjects and ten patients with systemic sclerosis affecting the lungs. Twenty millicuries (mCi) each of ${ }^{99 m} \mathrm{TcO}_{4}$ and ${ }^{99 \mathrm{~m}} \mathrm{Tc}-\mathrm{DTPA}$ in $5 \mathrm{ml}$ saline were aerosolised and inhaled using a disposable "Blount" nebuliser on two different days. Two regions of interest over each posterior lung field were monitored with a scintillation camera, and data were stored on magnetic tape using a Hewlett Packard Data Analyser. Decreasing levels of radioactivity were plotted semilogarithmically and half-time $\left(T \frac{1}{2}\right)$ removal rates were calculated. The $T \frac{1}{2}$ values in normal subjects did not differ significantly from $\mathrm{T} \frac{1}{2}$ values of the patients with $\mathrm{TcO}_{4}$. However, the removal rates of the higher molecular weight solute were significantly faster from lower lung zones in patients with systemic sclerosis than in the normal subjects. The faster absorption of DTPA from lower lung zones of the patients could be due to regional abnormalities of alveolar epithelium at the lung bases, presumably as a result of greater retractive forces secondary to fibrosis.
\end{abstract}

Lung clearance after inhalation of various absorbable radioaerosols was first studied in 1968 as a method for detecting regional impairment of alveolar-capillary membrane diffusion (Taplin and Isawa, 1968). Initial trials were unsuccessful, and further studies were deferred pending the availability of suitable imaging equipment. Recent improvements in aerosol administration and the advent of scintillation cameras capable of rapid sequential lung imaging and data display from selected areas of interest led us to study the clearance of soluble radioaerosols of different molecular weights from the lungs of healthy subjects and patients with systemic sclerosis affecting the lungs.

\section{Methods}

SUBJECTS

Seven normal subjects (28-60 years of age, mean $45.1)$ and ten patients with systemic sclerosis (3654 , mean $47 \cdot 6$ ) with affected lungs were studied.
All patients were non-smokers. The criteria for lung involvement was indicated by a vital capacity (VC) or total lung capacity (TLC) less than $80 \%$ of predicted, a single breath carbon monoxide transfer factor (TLCO) less than $75 \%$ expected, or roentgenographic evidence of a diffuse interstitial pulmonary process. All patients were currently participating in studies of systemic sclerosis at the UCLA Clinical Research Center. The study was approved by the human subject protection committee, and informed consent was obtained from each subject.

All subjects underwent spirometry, determination of the subdivisions of lung volumes by helium-dilution, TLCO, and static lung compliance using techniques described previously by Bjerke et al (1978).

On two separate days radioaerosol lung imaging was performed in the posterior projection after inhalation in the upright position of aerosols of sodium pertechnetate $\left({ }^{99 m} \mathrm{TcO}_{4}\right)$ (mol wt 163) or 
Table 1 Pulmonary function tests

\begin{tabular}{|c|c|c|c|c|c|c|c|c|}
\hline $\begin{array}{l}\text { Subject } \\
\text { No }\end{array}$ & $\begin{array}{l}\text { Age } \\
\text { (years) }\end{array}$ & Sex & $\begin{array}{l}\text { Forced vital } \\
\text { capacity } \\
(\% \text { pred })\end{array}$ & $\begin{array}{l}\text { Forced expiratory } \\
\text { volume }(1 \mathrm{sec}) \\
(\% \text { pred })\end{array}$ & $\begin{array}{l}\text { Total lung } \\
\text { capacity } \\
(\% \text { pred })\end{array}$ & $\begin{array}{l}\text { Transfer } \\
\text { factor } \\
(\% \text { pred })\end{array}$ & $\begin{array}{l}\text { Static compliance } \\
\left(\mathrm{l} / \mathrm{CmH}_{2} \mathrm{O}\right)\end{array}$ & $\begin{array}{l}\text { Coefficient of } \\
\text { retraction } \\
\left(\mathrm{cmH}_{2} \mathrm{O} / \mathrm{l}\right)\end{array}$ \\
\hline 1 & 37 & $\mathrm{~F}$ & 44 & 53 & 54 & 46 & 0.03 & $21 \cdot 1$ \\
\hline 2 & 52 & $\mathrm{~F}$ & 102 & 116 & 128 & 76 & 0.14 & $4 \cdot 2$ \\
\hline 3 & 54 & $\mathbf{F}$ & 103 & 105 & 119 & 65 & $0 \cdot 16$ & $4 \cdot 9$ \\
\hline 4 & 49 & $\mathbf{F}$ & 98 & 98 & 104 & 86 & 0.12 & $7 \cdot 6$ \\
\hline 5 & 50 & $\mathbf{F}$ & 94 & 109 & 105 & 81 & 0.14 & $6 \cdot 2$ \\
\hline 6 & 45 & $\mathbf{M}$ & 65 & 77 & 74 & 65 & $0 \cdot 15$ & $8 \cdot 5$ \\
\hline 7 & 46 & $\mathbf{M}$ & 116 & 133 & 128 & 94 & 0.25 & $4 \cdot 5$ \\
\hline 8 & 53 & $\mathbf{F}$ & 61 & 68 & 80 & 75 & $0 \cdot 13$ & $7 \cdot 7$ \\
\hline 9 & 36 & $\mathbf{F}$ & 38 & 47 & 43 & 22 & 0.02 & 20.8 \\
\hline 10 & 54 & $\mathbf{F}$ & 93 & 96 & 107 & 43 & 0.14 & 3.7 \\
\hline Mean & $47 \cdot 6$ & & $81 \cdot 4$ & $90 \cdot 2$ & $94 \cdot 2$ & $65 \cdot 3$ & 0.12 & $8 \cdot 9$ \\
\hline$\pm \mathrm{SD}$ & 6.6 & & $27 \cdot 1$ & $28 \cdot 1$ & 30.0 & $22 \cdot 4$ & 0.07 & $6 \cdot 6$ \\
\hline
\end{tabular}

${ }^{99 \mathrm{~m}} \mathrm{Tc}$-diethylenetriaminepenta-acetate (DTPA, mol wt 492). Twenty $\mathrm{mCi}$ of either solute were placed in a disposable "Blount" nebuliser that was driven by compressed air or oxygen at a flow rate of about $101 / \mathrm{min}$. A six litre plastic reservoir-settling bag was interposed in the inhalation line between the nebuliser and the subject's mouthpiece to remove droplets larger than $2.0 \mu \mathrm{m}$, and previous studies in our laboratory have shown the resultant aerosol to consist of 0.5 to $2.0 \mu \mathrm{m}$ particles. The subjects inhaled the aerosol during normal tidal breathing for two to three minutes or until about $2.0 \mathrm{mCi}$ were retained in the lung. During aerosol administration and for 20 minutes thereafter subjects were seated with their backs against the collimator of a gamma scintillation camera. Imaging data were stored on magnetic tape using a Hewlett Packard Data Analyser. Two regions of interest of equal size were selected over the peripheral portions of the upper and lower lung fields posteriorly on each side. Time-activity curves of decreasing levels of radioactivity were plotted semilogarithmically, and half-time lung removal rates ( $T \frac{1}{2}$ values) were calculated during the first ten minutes after aerosol inhalation. These curves were derived from $1 \mathrm{~cm} \times 1 \mathrm{~cm}$ areas $0.5 \mathrm{~cm}$ above the base and below the apex.

\section{Results}

Table 1 summarises the results of pulmonary function tests in the ten patients with systemic sclerosis. Seven had a reduction in TLCo, eight had a decreased static lung compliance, and three had a decreased total lung capacity. The normal (control) subjects had completely normal tests of lung function. Patients 4, 5, and 7, whose lung function was not very abnormal, had clear radiographic signs of pulmonary fibrosis.

Table 2 lists the rates of clearance of the lower molecular weight solute, $\mathrm{TcO}_{4}$, from the lungs.
Table 2 Sodium pertechnetate $\left(\mathrm{TcO}_{4}\right)$ absorption rates $\left(\mathrm{T} \frac{1}{2}=\right.$ min $)$

\begin{tabular}{|c|c|c|c|c|}
\hline \multirow{2}{*}{$\begin{array}{l}\text { Subject } \\
\text { No }\end{array}$} & \multicolumn{2}{|c|}{ Normal subjects } & \multicolumn{2}{|c|}{$\begin{array}{l}\text { Patients with systemic } \\
\text { sclerosis }\end{array}$} \\
\hline & Upper zone & Lower zone & Upper zone & Lower zone \\
\hline $\begin{array}{l}1 \\
2 \\
3 \\
4 \\
5 \\
6 \\
7 \\
8 \\
9 \\
10 \\
\text { Mean } \\
\text { SD } \\
\text { SE } \\
\text { P value }\end{array}$ & $\begin{array}{r}8 \cdot 9 \\
8 \cdot 7 \\
4 \cdot 5 \\
7 \cdot 1 \\
9 \cdot 4 \\
10 \cdot 2 \\
7 \cdot 7\end{array}$ & $\begin{array}{r}9.8 \\
12.3 \\
10.7 \\
9.0 \\
12.1 \\
11.8 \\
8.9\end{array}$ & $\begin{array}{l}5 \cdot 3 \\
7 \cdot 6 \\
6 \cdot 1 \\
6 \cdot 7 \\
6 \cdot 6 \\
5 \cdot 7 \\
8 \cdot 1 \\
5 \cdot 5 \\
5 \cdot 0 \\
6 \cdot 1 \\
6 \cdot 2 \\
0 \cdot 99 \\
0 \cdot 31 \\
\\
N S \dagger\end{array}$ & $\begin{array}{c}10.4 \\
10.0 \\
8 \cdot 6 \\
12 \cdot 8 \\
10.6 \\
7 \cdot 8 \\
10 \cdot 1 \\
13 \cdot 3 \\
5 \cdot 0 \\
8 \cdot 6 \\
9.7 \\
2.4 \\
0.76 \\
<0.05^{*} \\
\text { NS } \ddagger\end{array}$ \\
\hline
\end{tabular}

*Compared with upper zone in each group (paired $t$ test) tCompared with upper zone of normal subjects (unpaired $t$ test) $\ddagger$ Compared with lower zone of normal subjects (unpaired $t$ test)

The $T \frac{1}{2}$ values in normal subjects averaged $8 \cdot 1 \pm 3$. 0.68 (SEM) min and $10.7 \pm 0.53$ (SEM) min from $\delta$ the upper and lower zones respectively. The $\mathrm{T} \frac{1}{2} \xi$ values in patients with systemic sclerosis averaged $\mathrm{O}$ $6 \cdot 2 \pm 0.31$ (SEM) $\mathrm{min}$ and $9 \cdot 7 \pm 0.76(\mathrm{SEM}) \mathrm{min}_{\supset}$ from the upper and lower lung zones respectively. 을 In both groups the solute cleared significantly more quickly $(P<0.05$, paired $t$ test) from upper $\odot$ than lower zones. Absorption rates, however, were $N$ not significantly different $(\mathrm{P}>0.05$, unpaired $t$ test $) \mathrm{\omega}^{N}$ either from the upper zones of normal subjects compared with the upper zones of systemice sclerosis or from the lower zones of normal subjects compared with the lower zones of patients? (fig 1).

Table 3 lists the rates of diffusion of the highero molecular weight solute, DTPA. Its $\mathrm{T}^{\frac{1}{2}}$ values averaged $35 \cdot 1 \pm 5.6(\mathrm{SEM})$ and $65.0 \pm 8.7(\mathrm{SEM}) \stackrel{\mathbb{Q}}{\mathrm{Q}}$ min from the upper and lower lung zones, respectively, of the normal subjects, whereas $\mathrm{T}^{\frac{1}{2}}$ values 


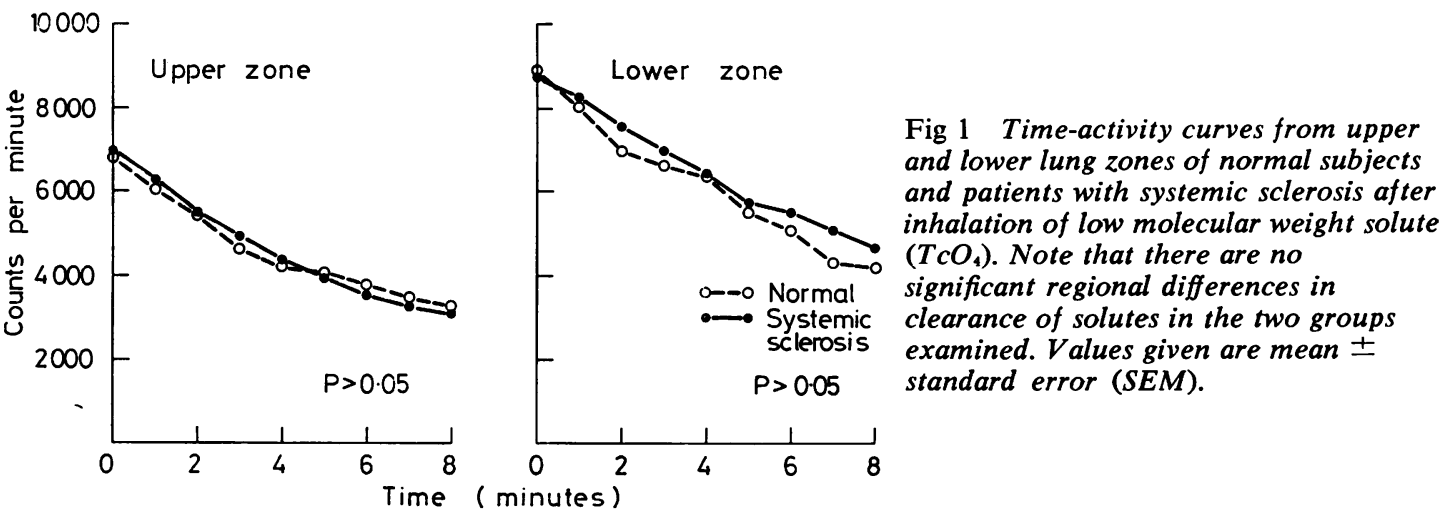

Table 3 Tc-DTPA absorption rates $\left(T \frac{1}{2}=\min \right)$

\begin{tabular}{|c|c|c|c|c|}
\hline \multirow[t]{2}{*}{$\begin{array}{l}\text { Subject } \\
\text { No }\end{array}$} & \multicolumn{2}{|c|}{ Normal subjects } & \multicolumn{2}{|c|}{$\begin{array}{l}\text { Patients with systemic } \\
\text { sclerosis }\end{array}$} \\
\hline & Upper zone & Lower zone & Upper zone & Lower zone \\
\hline $\begin{array}{l}1 \\
2 \\
3 \\
4 \\
5 \\
6 \\
7 \\
8 \\
9 \\
10 \\
\text { Mean } \\
\text { SD } \\
\text { SE } \\
\text { P value }\end{array}$ & $\begin{array}{l}29 \\
37 \\
44 \\
26 \\
22 \\
34 \\
19 \\
81 \\
32 \\
27 \\
35 \cdot 1 \\
17 \cdot 7 \\
5 \cdot 6\end{array}$ & $\begin{array}{l}89 \\
91 \\
99 \\
20 \\
38 \\
96 \\
45 \\
66 \\
59 \\
47 \\
65.0 \\
27.6 \\
8.7 \\
<0.05^{*}\end{array}$ & $\begin{array}{r}14 \\
68 \\
8 \\
18 \\
30 \\
14 \\
33 \\
40 \\
24 \\
13 \\
26 \cdot 2 \\
17 \cdot 9 \\
5 \cdot 7 \\
\\
\text { NS } †\end{array}$ & $\begin{array}{l}30 \\
49 \\
11 \\
64 \\
35 \\
20 \\
64 \\
32 \\
40 \\
34 \\
37.9 \\
17 \cdot 1 \\
5.4 \\
<0.05^{*} \\
<0.05 \ddagger\end{array}$ \\
\hline
\end{tabular}

*Compared with upper zone in each group (paired $t$ test)

†Compared with upper zone of normal subjects (unpaired $t$ test)

+Compared with lower zone of normal subjects (unpaired $t$ test)

averaged $26.9 \pm 5.7($ SEM) and $37.9 \pm 5.4$ (SEM) min from the upper and lower zones, respectively, of the patients with systemic sclerosis. In both groups the absorption rates were significantly faster $(\mathrm{P}<0.05$, paired $t$ test) from the upper than the lower zones. The most important finding of this study was that the absorption rates were significantly faster $(\mathrm{P}<0.05$, unpaired $t$ test $)$ from the lower lung zones of patients than from the lower zones of normal subjects (fig 2).

The $T \frac{1}{2}$ clearance values for DTPA from the lower zones in systemic sclerosis were not correlated with the lung compliance, coefficient of retraction, or percentage of predicted TLCo (fig 3).

\section{Discussion}

The mechanisms involved in the removal of aqueous solutes from the lung are not clearly understood. Particulate material can be removed from the lung by at least three mechanismsnamely, (a) mucociliary transport, (b) blood capillaries, and $(c)$ lymphatics.

The maximum size of the aqueous aerosol droplets produced by the Blount nebuliser-delivery

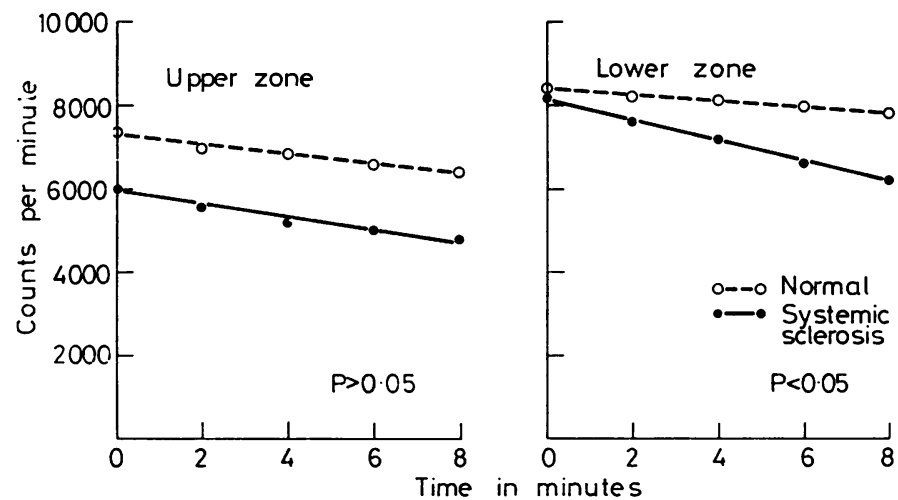

Fig 2 Time-activity curves from upper and lower lung zones of normal subjects and patients with systemic sclerosis after inhalation of higher molecular weight solute (DTPA). Note that clearance of tracer is significantly faster from lower lung zones of patients. Values given are mean \pm standard error (SEM). 

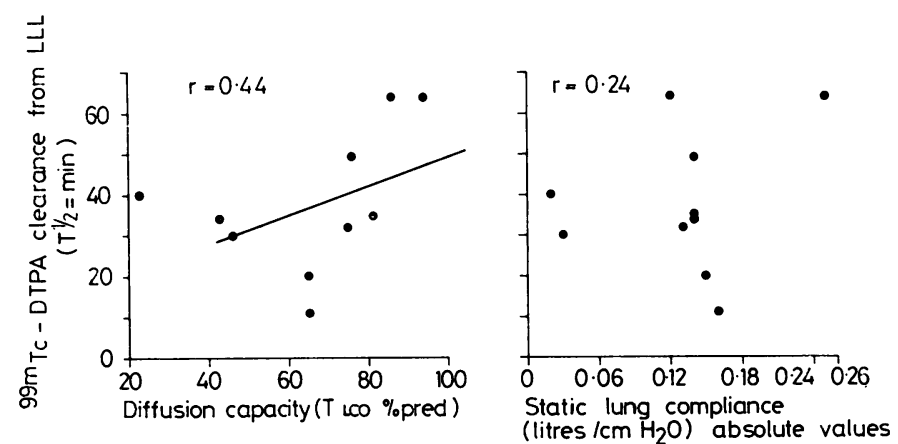

Fig 3 Graphs showing relation between clearance of DTPA from lower lung zones of patients with systemic sclerosis and (a) transfer factor (TLCo) and (b) static recoil pressure. Note that there is a weak inverse correlation with TLCO and no correlation with Pst.

system used in this study is most likely less than $2.0 \mu \mathrm{m}$. About $80 \%$ of initially deposited insoluble aerosols of this size penetrates beyond the ciliated airways and remains in the lungs longer than 24 hours in normal subjects (Morrow et al, 1967; Taplin and Chopra, 1978). The rapid removal of radiolabelled soluble aerosols from the lungs of our subjects ( $\mathrm{T} \frac{1}{2}$ values, $6-60 \mathrm{~min}$ ) is most likely to be accomplished by mechanisms other than mucociliary transport, which requires a much longer time for clearance of activity from the distal tracheobronchial tree.

The faster clearance of both solutes $\left(\mathrm{TcO}_{4}\right.$ and DTPA) from the upper than the lower lung zones in normal subjects suggests that the removal of these solutes occurs by mechanisms other than perfusion (which is greater at the bases) and thus differs from the clearance of ${ }^{11} \mathrm{CO}$, which is partly blood flow related (Taplin et al, 1976). The volume of alveolar spaces is fairly uniform throughout the lung at total lung capacity in normal subjects (Milic-Emili et al, 1966). At the end of both a normal expiration (functional residual capacity-FRC) and a maximal expiration (residual volume-RV), however, the alveoli in the apical lung regions are larger than those at the lung bases (Milic-Emili et al, 1966; Sutherland et al, 1968). During tidal volume breathing, the alveolar size decreases approximately linearly with distance down the lung. Therefore, the larger size of alveoli at the apex provides a greater surface area for diffusion of radioactive solutes and may be a factor in the faster diffusion from the upper than from the lower lung zones.

Absorption of radioaerosols may possibly occur via the lymphatics, which play an important part in the removal of many other agents (Leak and Burke, 1968; Meyer et al, 1969). The close proximity between the alveolar lymphatics and peribronchial lymphatic plexus as shown by electron microscopy (Casley-Smith, 1964; Leak and Burke, 1968; Lauweryns and Boussauw, 1969) also suggests that the lymphatics may play a part in lung removal of soluble aerosols.

The finding that a smaller molecular weight solute $\left(\mathrm{TcO}_{4} ; 163\right)$ is cleared from the distal air spaces more rapidly than a larger molecular weight solute (DTPA; 492) in normal subjects is consistent with the hypothesis that the clearance of aqueous solutes through the alveolar epithelium is dependent on molecular size in relation to the size of the pores between the epithelial cells. The more rapid clearance of DTPA from the lower zones in systemic sclerosis compared with normal subjects might be caused by widening of interepithelial junctions, possibly from an increasing retractive force secondary to fibrosis, which predominantly affects the lung bases in systemic sclerosis. No correlation was shown to exist in this study, however, between the rate of DTPA clearance and degree of reduction in static lung compliance. This discrepancy may be explained in two ways-regional fibrosis may not give a measurable overall reduction in lung compliance or involvement of the oesophagus in systemic sclerosis may produce spurious abnormalities in the measurement of compliance.

These new observations with soluble agents open 옥 another area of investigation with radioaerosols- $->$ that is, "cold spot" imaging to detect regional o lung abnormalities in patients with interstitial lung $N$ disease because clearance of the higher molecular $\sigma$ weight solute is faster from diseased than from normal lung.

This work was supported by contract $\mathrm{E}(04-10) \stackrel{0}{\overparen{D}}$ Gen-12 between the US Energy Research and $\stackrel{\odot}{\rightarrow}$ Development Agency and the University of 0 California and USPHS grant GM 15959 and RR 0865.

We are grateful to Dr Philip Clements, Maureen Van Dell, and Joanne Leynnwood for help in this work. 


\section{References}

Bjerke, R D, Tashkin, D P, Clements, P J, Chopra, S K, Gong, H, Bein, M (1978). Small airways in progressive systemic sclerosis. American Journal of Medicine. In press.

Casley-Smith, J R (1964). An electron microscopic study of injured and abnormally permeable lymphatics. Annals of the New York Academy of Sciences, 116, 803-830.

Lauweryns, J M, and Boussauw, L (1969). The ultrastructure of pulmonary lymphatic capillaries of newborn rabbits and of human infants. Lymphology, 2 , 108-129.

Leak, L V, and Burke, J F (1968). Electron microscopic study of lymphatic capillaries in the removal of connective tissue fluids and particulate substances. Lymphology, 1, 39-52.

Meyer, E C, Dominquez, E A M, and Bensch, K G (1969). Pulmonary lymphatic and blood absorption of albumin from alveoli. A quantitative comparison. Laboratory Investigations, 20, 1-8.

Milic-Emili, J, Henderson, J A M, Dolovich, M B, Trop, D, and Kaneko, K (1966). Regional distribution of inspired gas in the lung. Journal of Applied Physiology, 21, 749-759.

Morrow, P E, Gibb, F R, and Gazioglu, K M (1967). A study of particulate clearance from the human lungs. American Review of Respiratory Disease, 96, 1209-1221.

Sutherland, P W, Katsura, T, and Milic-Emili, J (1968). Previous volume history of the lung and regional distribution of gas. Journal of Applied Physiology, 25, 566-574.

Taplin, G V, and Isawa, T (1968). Regional alveolar liquid diffusibility by lung scintigraphy. In Semiannual Progress Report Submitted to USAEC, $U C L A$ 12-686, UC-48 Biology and Medicine, pp $4-$ 43, TID 4500. (Available from Clearinghouse for Federal Scientific and Technical Information, National Bureau of Standards, US Dept of Commerce, Springfield, VA 25151).

Taplin, G V, and Chopra, S K (1978). Inhalation lung imaging with radioactive aerosols and gases. In Progress in Nuclear Medicine, edited by M Guter. S Karger, Basel-Munchen, Paris, London, New York, Sydney. In press.

Taplin, G V, Chopra, S K, Macdonald, N S, and Elam, D (1976). Imaging small pulmonary ischemic lesions after radioactive carbon monoxide inhalation. Journal of Nuclear Medicine, 17, 866-871.

Requests for reprints to: S K Chopra, MD, Division of Pulmonary Diseases, Department of Medicine, UCLA School of Medicine, Los Angeles, California 90024.

\section{International Congress on Respiratory Diseases}

\section{0-13 October 1979, Basel, Switzerland.}

President: Professor Dr H Herzog.

Main topic: Asthma

including workshop on exogenous diffuse fibrosing alveolitis.

Plenary lectures and free papers.

For further information and documentation please contact: Administrative Secretariat, PO Box 182, CH-4013 Basel, Switzerland. 